
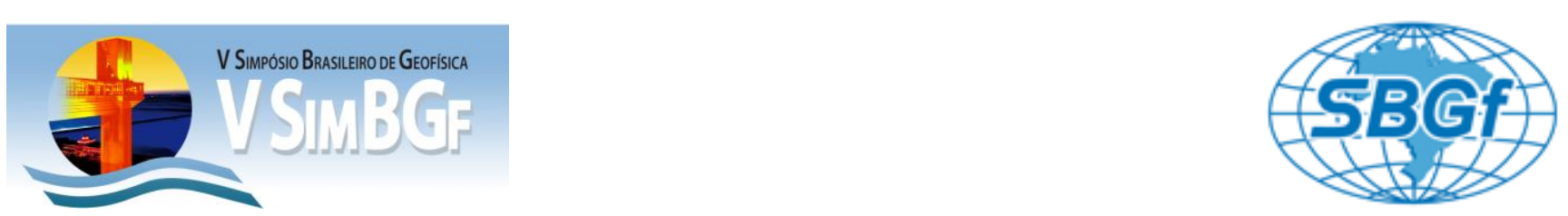

\title{
Aplicação do método gamaespectrométrico terrestre em escala de detalhe para a caracterização de ocorrências minerais na localidade Cerro dos Martins, Caçapava do Sul - RS.
}

Dione Fontoura dos Santos ${ }^{1}$, Mario Jesus Tomas Rosales ${ }^{1}$, Delia Del Pilar Montecinos de Almeida1 , Renato Luiz da Silveira ${ }^{1}$. Universidade Federal do Pampa ${ }^{1}$

Copyright 2012, SBGf - Sociedade Brasileira de Geofísica

Este texto foi preparado para a apresentação no V Simpósio Brasileiro de Geofísica, Salvador, 27 a 29 de novembro de 2012. Seu conteúdo foi revisado pelo Comitê Técnico do V SimBGt, mas não necessariamente representa a opinião da SBGf ou de seus associados. É proibida a reprodução total ou parcial deste material para propósitos comerciais sem prévia autorização da SBGf.

\section{Resumo}

Este trabalho consiste na aplicação do método geofísico gamaespectrométrico terrestre em escala de detalhe, integrando seus resultados a dados geológicos e topográficos compilados e levantados em campo, com a finalidade de contribuir para a atualização do estudo geológico-geofísico na área do Cerro dos Martins no município de Caçapava do Sul - RS. A área se encontra delimitada geograficamente pelas latitudes $30^{\circ} 42^{\prime} 38.12^{\prime \prime}$ e $30^{\circ} 43^{\prime} 01.08^{\prime \prime} \mathrm{S}$ e pelas longitudes $53^{\circ} 27^{\prime} 21.00^{\prime \prime}$ e $53^{\circ}$ $27^{\prime} 43.85$ W. Geologicamente a área se caracteriza pela presença de um conjunto de veios sulfetados preenchendo fraturas de direção N40-60W, nos andesitos e nas rochas sedimentares clásticas, com disseminações confinadas em níveis de siltito e arenito, pertencentes ao Grupo Bom Jardim. O levantamento gamaespectrométrico consistiu em 188 pontos físicos medidos em campo, distribuídos regularmente com um espaçamento aproximado de 30 metros. Obtiveram-se como produtos gráficos finais mapas de imagens dos canais de $\mathrm{K}(\%)$, eU (ppm), eTh (ppm) e de Contagem total (ppm). Resultados significativos mostram altos anômalos nos canais de $\mathrm{K}(\%)$, eU (ppm), na porção central da área de estudo associados a prováveis zonas de mineralização hidrotermal.

\section{Introdução}

Em um contexto geológico regional no Escudo Sul-RioGrandense localizam-se ambientes favoráveis à mineralização de metais básicos, sobre tudo do tipo filoniano. É constituído de rochas de idade Précambriana, nas quais se ressaltam a importância econômica do conjunto litológico compreendido entre as formações Vacacaí ( $\approx 753 \mathrm{Ma}$ ) e Santa Bárbara $(\approx 542$ $\mathrm{Ma})$, com destaque especial para as unidades do Grupo Bom Jardim ( $~ 580 \mathrm{Ma})$. São inúmeras as ocorrências de cobre registradas, entre elas o Depósito Cerro dos Martins.

$\mathrm{Na}$ área, afloram rochas que fazem parte da sequência vulcanossedimentar Bom Jardim, formada por andesitos da Formação Hilário de idade $590 \pm 5.7$ Ma (Janikian et al. 2008) e $591 \pm 3.0$ (Almeida et al. 2012).

O trabalho consiste na realização de um levantamento gamaespectrométrico terrestre em escala de detalhe, em uma área que abrange aproximadamente $4.2 \mathrm{~km}^{2}$, cobrindo uma malha regular com espaçamento entre pontos de medição de aproximadamente 30 metros. A finalidade do trabalho é contribuir para o esclarecimento do mapeamento geológico de detalhe na área de estudo e para a caracterização geofísica das ocorrências minerais na localidade Cerro dos Martins.

\section{Área de estudo}

A região de estudo está situada na localidade Cerro dos Martins, no município de Caçapava do Sul - RS, delimitada geograficamente pelas latitudes $30^{\circ} 42$ ' $38.12^{\prime \prime}$ e $30^{\circ} 43^{\prime} 01.08^{\prime \prime} \mathrm{S}$ e pelas longitudes $53^{\circ} 27^{\prime} 21.00^{\prime \prime}$ e $53^{\circ}$ $27^{\prime} 43.85^{\prime \prime} \mathrm{W}$, conforme ilustrado na Figura 1.

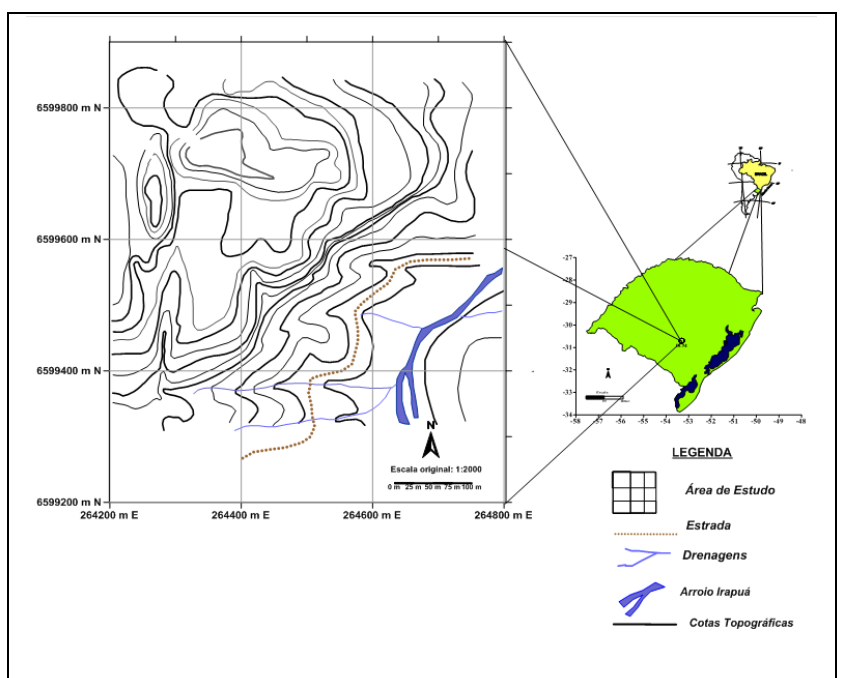

Figura 1- Mapa de localização da área de estudo, modificado de CBC, (1978).

\section{Arcabouço geológico}

A área de estudo que compreende o depósito Cerro dos Martins, consiste de um conjunto de veios sulfetados preenchendo fraturas de direção $\mathrm{N} 40^{\circ}-60^{\circ} \mathrm{W}$, em andesitos e rochas sedimentares clásticas, com 
disseminações confinadas em níveis de siltitos e arenitos pertencentes ao Grupo Bom Jardim.

Segundo se mostra no mapa geológico da Figura 2, rochas andesíticas afloram na porção noroeste, afetadas tectonicamente por falhamentos com direção NW, na porção central aparecem expostos indistintamente pacotes de arenitos e de conglomerados, pertencentes à Formação Hilário e na porção sudeste expõe-se depósitos aluvionares caracterizados pela presença de sedimentos sílticos-argilosos, areias e cascalhos.

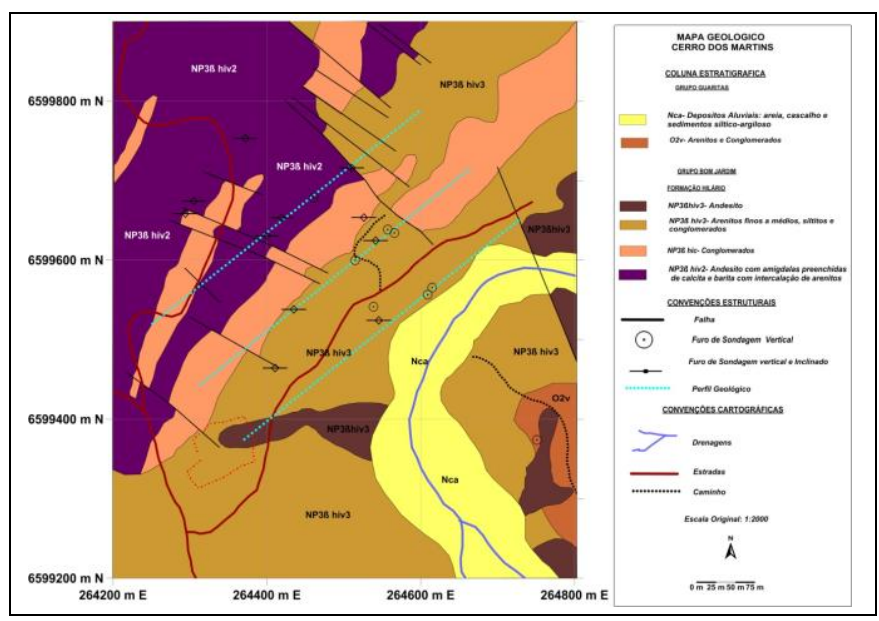

Figura 2 - Mapa geológico da localidade do Cerro dos Martins, modificado de CBC (1978).

\section{Dados topográficos}

Os dados de altitudes ortométricas utilizados neste trabalho são oriundos do levantamento topográfico executado pelo DAER (Departamento Autônomo Estradas e Rodagens) em 1978 na pesquisa da DOCEGEO encomendado pela CBC.

\section{Gamaespectrometria terrestre}

Os levantamentos gamaespectrométricos são amplamente utilizados no mapeamento geológico, pois diferentes tipos de litologias podem ser identificadas por suas assinaturas radiométricas (Kearey, 2009). Os valores médios característicos para a crosta terrestre destes elementos são: $2 \%$ para o Potássio (K); 2,7ppm para o Urânio (U) e de 8,5 ppm para o Tório (Th).

Os dados gamaespectrométricos terrestres compreendem um total de 188 pontos físicos medidos em uma malha regular com espaçamento aproximado de 30 metros. Foram adquiridos com o gamaespectrômetro $R S$ 230 BGO Super Spec, fabricado pela Radiation Solutions Inc - Canadá, composto por um detector de cristal de óxido de germanato de bismuto (6,3 cu ins), pertencente à UNIPAMPA.

A distribuição dos dados gamaespectrométricos na área de estudo se ilustra na Figura 3.

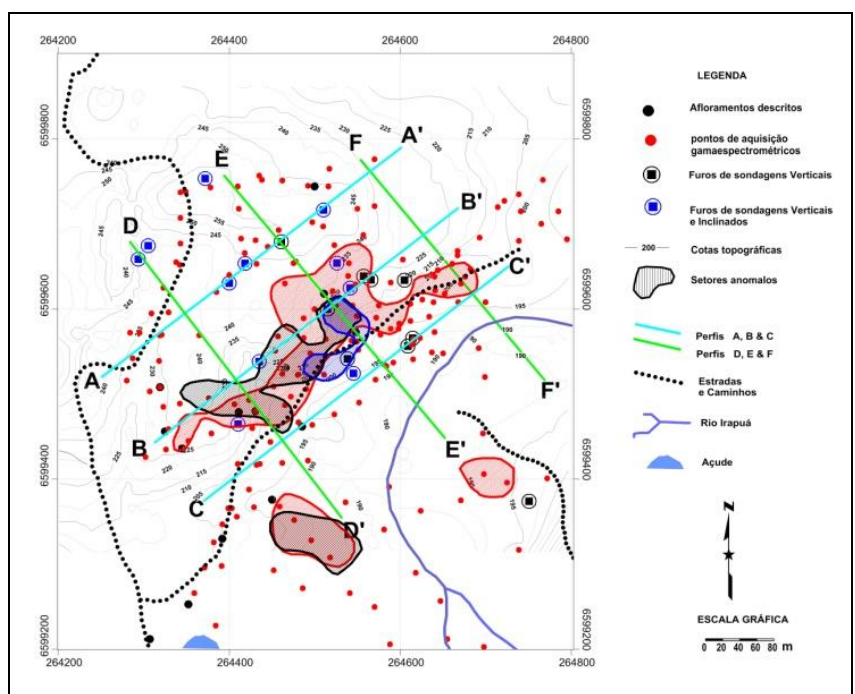

Figura 3 - Mapa esquemático de distribuição dos dados gamaespectrométricos na área de estudo.

A aquisição dos dados gamaespectrométricos no campo foi conforme a configuração no modo -ASSAY- com intervalo de leitura de 2 minutos.

As leituras gamaespectrométricas foram tomadas para cada um dos canais, em contagens por segundo (cps), e automaticamente transformadas em concentrações de $\mathrm{K}$ (\%), de eU (ppm) e eTh (ppm), com base em procedimentos de calibração realizados pelo próprio fabricante do instrumento.

Aos dados adquiridos em campo, foi feita a correção do Background atmosférico e posteriormente no processamento dos dados foi ulitilzado o algorítmo de mínima curvatura para a geração de mapas de imagens dos canais de Potássio (\%), eU (ppm) e eTh (ppm), assim como de contagem total (ppm), para a área de estudo.

\section{Resultados Preliminares}

Os resultados dos dados gamaespectrométricos, foram expressos através de mapas de imagens para os canais de Potássio (K \%), de Urânio (eU ppm), de Tório (eTh ppm) e de Contagem Total (ppm). Nas figuras 4(a), 4(b), $4(c)$ e $4(d)$ se ilustram o comportamento de cada radioelemento na área de estudo.

\section{Potássio - K (\%)}

As concentrações de $\mathrm{K}(\%)$ observadas no mapa da Figura 4(a) mostram altos anômalos com valores de 4.6 $\%$, e valores médios em torno de $1.92 \%$.

Destacam-se duas anomalias com valores na ordem de $2.9 \%-3 \%$, localizadas na porção central, provavelmente 
associadas à presença de feldspatos potássicos presentes nos conglomerados da Formação Hilario ( $\approx$ $590 \mathrm{Ma})$ do Grupo Bom Jardim.

\section{Equivalente de Urânio - eU (ppm)}

O urânio ocorre em baixa concentração na crosta terrestre (aproximadamente $3 \mathrm{ppm}$ ), sendo quimicamente dominado por seus estados de valência $U+4$ e $U+6$. O primeiro estado geralmente está contido em minerais não solúveis, enquanto o segundo associa-se com ânions nos carbonatos, sulfatos e fosfatos para formarem espécies solúveis (Dickson \& Scott, 1997).

As concentrações de eU (ppm) observadas no mapa da Figura 4(b) mostram altos valores em torno de $2.0 \mathrm{ppm}$, com valores médios em torno de 0.8 ppm - 0.9 ppm.

$\mathrm{Na}$ porção central da área se destacam quatro anomalias de eU (ppm) alinhadas na direção nordeste, localizadas espacialmente nas proximidades do contato entre os andesitos e os conglomerados da Formação Hilario ( $590 \mathrm{Ma})$.

\section{Equivalente de Tório - eTh (ppm)}

Segundo Dickson \& Scott (1997), o tório pode ocorrer em alanita, monazita, xenotímeo e zircão, em concentrações maiores que 1000 ppm ou em quantidades-traço em outros minerais constituintes das rochas. Em rochas sedimentares a concentração varia de $0,8 \mathrm{ppm}-6,1 \mathrm{ppm}$ e em solos de origem sedimentar de 2,9 ppm - 8,4 ppm. Sendo que os valores médios característicos de concentração na crosta terrestre variam entre 8 ppm e 12 ppm.

A Figura 4(c) mostra o mapa de imagem das concentrações de eTh(ppm) para a área de estudo. Ressalta-se na porção central a presença de uma anomalia com um formato alongado com o eixo principal na direção nordeste, com valores em torno de 9.0 ppm $10 \mathrm{ppm}$, associada provavelmente a presença de argilominerais contendo hidróxidos de ferro em zonas de alteração hidrotermal observadas em alguns afloramentos de conglomerados.

\section{Contagem Total - CT (ppm)}

A Figura 4(d) mostra o mapa de imagem para o canal de Contagem Total (ppm). Ressaltam-se na porção central a presença de três altos anômalos com o eixo preferencial orientado segundo a direção nordeste, com valores em torno de $800 \mathrm{ppm}$ - $850 \mathrm{ppm}$. O fato do canal de Contagem Total (ppm), ter uma contribuição integrada das respostas dos três canais provenientes do $\mathrm{K}(\%)$, eU (ppm) e do eTh (ppm), corrobora de alguma maneira a presença de altas concentrações dos radioelementos indicados, associados ao contato das zonas de alteração hidrotermal afetadas por falhamentos segundo a direção NW, conforme ilustrado na mapa geológico da Figura 2.

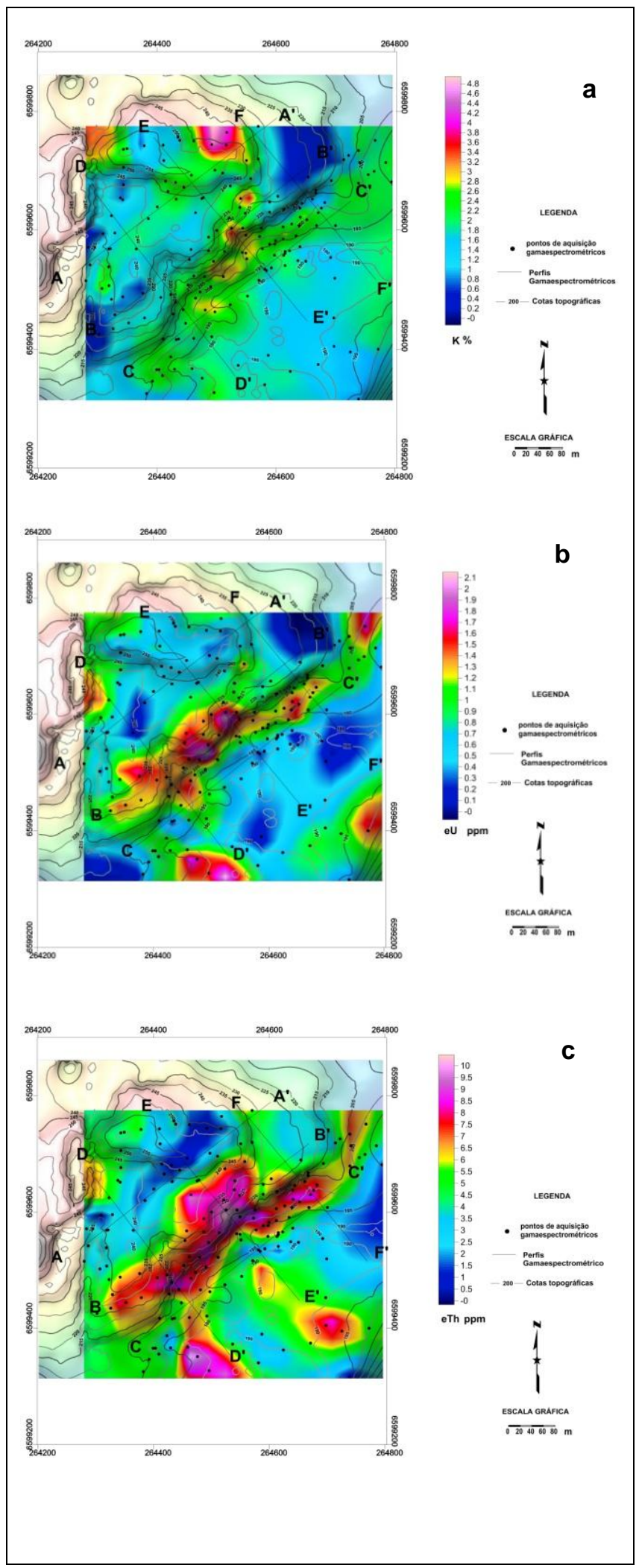




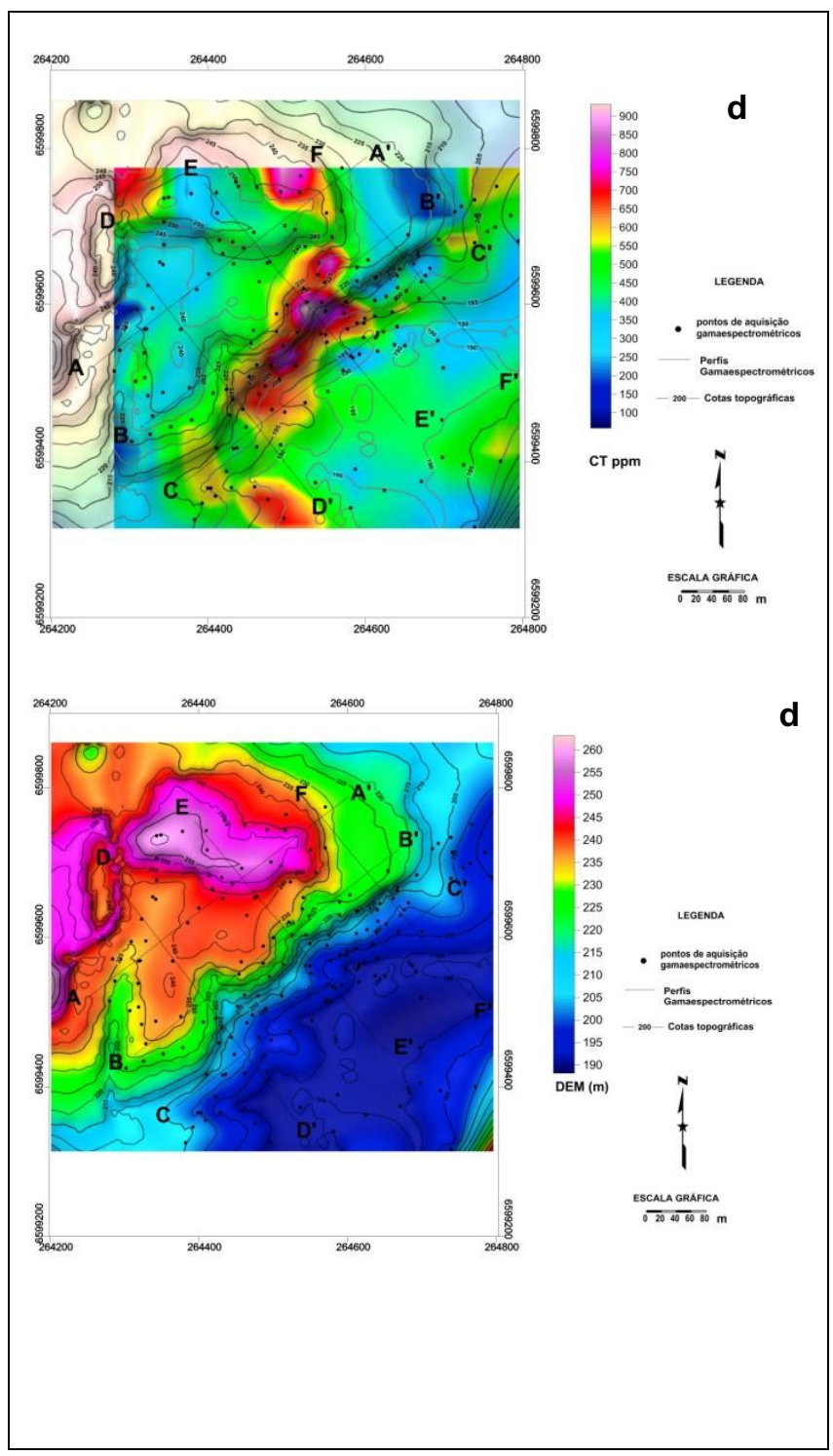

Figura 4 - Mapas de imagens para os canais de $K \%$ (a), eU ppm (b), eTh ppm (c) e de Contagem Total ppm (d). Mapa de imagem do relevo topográfico da área de estudo (e).

\section{Análise Espectral dos dados gamaespectrométricos}

A Figura 5 mostra dois gráficos de espectros de energia referentes aos pontos de medições gamaespectrométricas localizados em setores anômalos localizados na porção central da área de estudo.

O sinal energético para o canal de $\mathrm{K}$ (\%) e para eU (ppm) referente ao ponto de medição 82 , revela um pico de energia mais intenso, se comparado com o ponto de medição 141, isto poderia estar associado a diferentes graus de alteração das rochas presentes na porção central da área de estudo conforme ilustrado na Figura 6 , onde destacam-se zonas de alteração hidrotermal com diferentes graus de alteração segundo o mapeamento geológico.

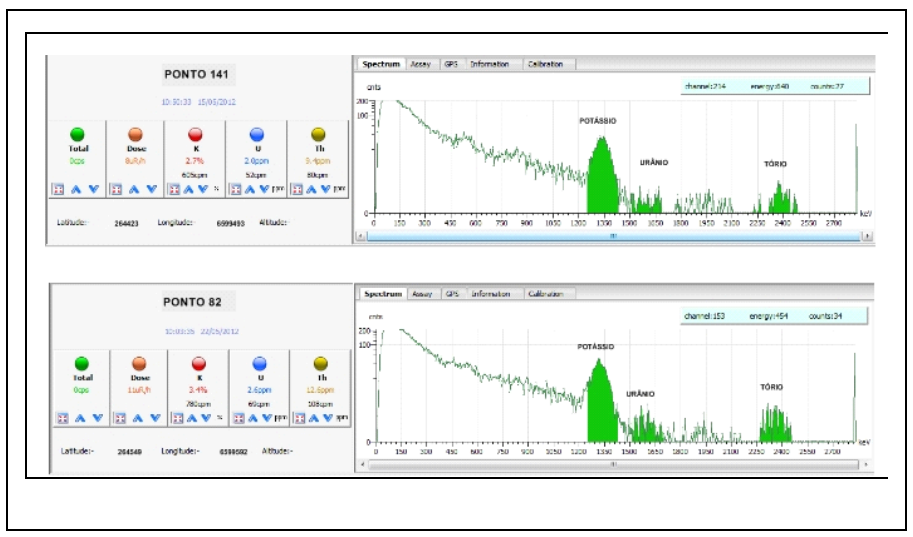

Figura 5 - Gráficos dos espectros de energia para os pontos de medições 141 e 82 localizados na porção central da área de estudo.

\section{Conclusões}

Os resultados preliminares obtidos destacam de maneira geral, um comportamento anômalo para os três canais dos radioelementos, Potássio (K \%), Urânio (eU ppm) e Tório (eTh ppm) na porção central da área de estudo, associado a presença de zonas de alteração hidrotermal observada macroscopicamente em campo.

A interpretação dos dados gamaespectrométricos de detalhe levantados em campo conjuntamente com os dados topográficos de alta resolução, demonstraram a eficiência desta metodologia como subsidio ao mapeamento geológico.

A pesquisa faz parte de um projeto de conclusão de curso em andamento, e tem como finalidade 0 esclarecimento de questões relacionadas com a gênesis e a geometria de corpos mineralizados existentes na região.

\section{Agradecimentos}

Nossos agradecimentos a CBC (Companhia Brasileira do Cobre) pelo acesso aos relatórios de pesquisa e a disponibilidade da área de estudo, e a Universidade Federal do Pampa (UNIPAMPA), Campus Caçapava do Sul, pelo apoio no transporte e pelos equipamentos cedidos.

\section{Referências}


ALMEIDA, D. DEL P. M. DE; CHEMALE JR., F MACHADO. 2012. A. Late to Post-Orogenic BrasilianoPan-AfricanVolcano-Sedimentary Basins in the Dom Feliciano Belt, Southernmost Brazil .in. Petrology - New Perspectives and Applications, Edited by Ali Ismail AlJuboury. $p 73-130$

COMPANHIA BRASILEIRA DE COBRE - CBC. 1978. Relatório de reavaliação na área do decreto №. 70.926 (DNPM 7566/64), Cerro dos Martins, município de Caçapava do Sul. Porto Alegre. 2 v. (Inédito).

DICKSON BL \& SCOTT KM. 1997. Interpretation of aerial gamma-ray surveys -adding the geochemical factors. AGSO Journal of Australian Geology \& Geophysics, Australia, 17(2): 187-200.

JANIKIAN, L.; ALMEIDA, R.; FERREIRA DA T.; FRAGOSO-CESAR, A. R.; SOUZA D'A., M.; DANTAS, E. \&TOHVER, E. (2008). The continental Record of Ediacaran volcano-sedimentary successions in southern Brazil and their global implications.Terra Nova, Vol. 20, pp.259-266, Publ. Online - doi: 10.1111/j.13653121.2008.00814.x, ISNN 0954-4879

KEAREY, PHILIP; BROOKS, MICHAEL; HILL, IAN. An Introduction to Geophysical Exploration. 3. ed. [s.I]. Blackwell. 2002. 262 p.

RADIATION SOLUTIONS INC. RS-230 BGO Super Spec. Canadá .Disponível em:

www.radiationsolutions.ca/index.php?id=4
RIO DOCE GEOLOGIA E MINERAÇÃO S. A. DOCEGEO. 1978. Relatório preliminar de pesquisa alvarás 2496/77, 3050/77, 3052/77 e 3051/77. Porto Alegre. 1 v. (Inédito). 


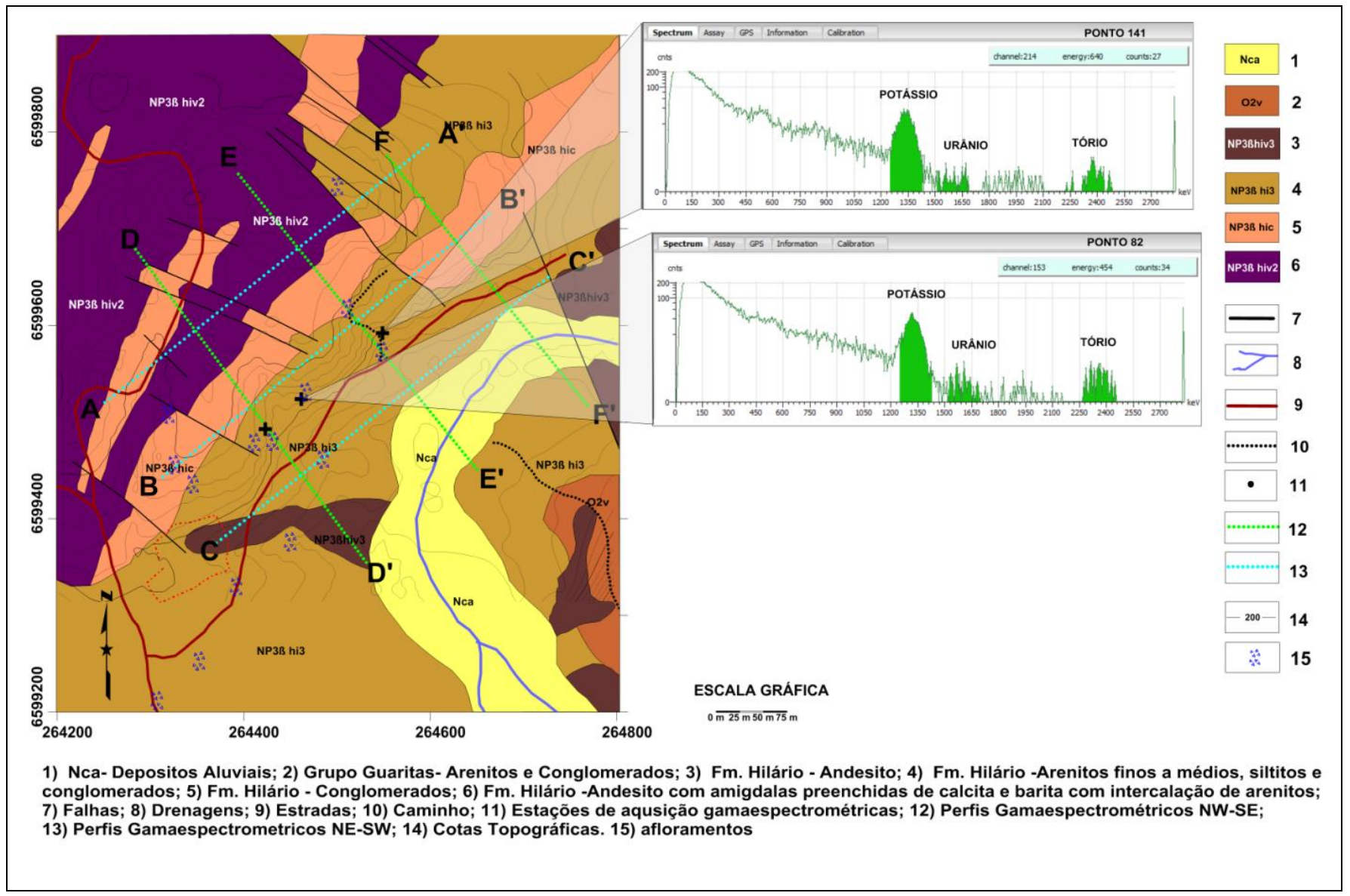

Figura 6- Mapa geológico com contorno topográfico integrado a dados de espectros radiométrico referentes a altos anômalos próximo a afloramentos observados em campo. 